Case Report

\title{
Acute Anterior Myocardial Infarction Accompanied by Acute Inferior Myocardial Infarction: A Very Rare Coronary Artery Anomaly
}

\author{
Y. Alsancak, ${ }^{1}$ B. Sezenöz, ${ }^{2}$ M. Duran, ${ }^{1}$ S. Unlu, ${ }^{3}$ S. Turkoglu, ${ }^{3}$ and R. Yalcın ${ }^{3}$ \\ ${ }^{1}$ Department of Cardiology, Ataturk Education and Research Hospital, Bilkent, Ankara, Turkey \\ ${ }^{2}$ Department of Cardiology, Gazi Mustafa Kemal State Hospital, Besevler, Yenimahalle, Turkey \\ ${ }^{3}$ Department of Cardiology, Medical Faculty, Gazi University, Besevler, Ankara, Turkey \\ Correspondence should be addressed to B. Sezenöz; drburaksezenoz@gmail.com
}

Received 3 March 2015; Revised 17 May 2015; Accepted 28 May 2015

Academic Editor: Monvadi Barbara Srichai

Copyright (C) 2015 Y. Alsancak et al. This is an open access article distributed under the Creative Commons Attribution License, which permits unrestricted use, distribution, and reproduction in any medium, provided the original work is properly cited.

Coronary artery anomalies are rare and mostly silent in clinical practice. First manifestation of this congenital abnormality can be devastating as syncope, acute coronary syndrome, and sudden cardiac death. Herein we report a case with coronary artery anomaly complicated with ST segment myocardial infarction in both inferior and anterior walls simultaneously diagnosed during primary percutaneous coronary intervention.

\section{Introduction}

Coronary artery anomalies (CAA) are a diverse group of congenital disorders whose manifestations and pathophysiological mechanisms are highly variable. Although most of the anomalies have clinically insignificant repercussions, some of them may have devastating impacts. In symptomatic patients, these anomalies manifest themselves as exercise induced angina, syncope, acute coronary syndrome, or in some cases sudden cardiac death. Sudden cardiac death associated with CAA is especially observed in the young [1].

\section{Case Report}

A 40-year-old male patient was admitted to emergency department with chest pain that had lasted one hour. His electrocardiogram (ECG) on presentation showed ST segment elevations in the precordial leads (Figure 1). Except for smoking there was no reported history of cardiac risk factor. On physical examination his blood pressure was $140 / 90 \mathrm{mmHg}$, heart rate 80 beats per minute, and oxygen saturation $96 \%$ on room air. His left ventricular functions were found to be depressed during 2D echocardiographic evaluation. After ruling out the possibility of aortic dissection we decided to perform fibrinolytic therapy. After receiving fibrinolytic therapy his chest pain was improved and partial ST segment resolution was observed on his ECG (Figure 2). Troponin level was $0,329 \mathrm{pg} / \mathrm{mL} .30$ minutes after administration of therapy his chest pain was worsened and his blood pressure dropped to $80 / 60 \mathrm{mmHg}$. His control ECGs showed new ST segment elevations in both the inferior and the precordial leads (Figure 3). He was immediately transferred to catheter laboratory for rescue percutaneous coronary intervention (PCI). His coronary angiography $(\mathrm{CA})$ revealed an anomalous right coronary artery (RCA) originating from the proximal portion of left anterior descending (LAD) coronary artery which was totally occluded (Figures 4-7). Also, his CA showed that there was a severe thrombotic occlusion in ostium of RCA and totally occluded circumflex artery (Figure 4). Afterwards, we consulted him about cardiovascular surgery for urgent surgery. Because of his unstable condition and progressive chest pain the patient was deemed an unsuitable candidate for surgery. Under these circumstances we decided to perform PCI. A floppy guide wire was advanced into the RCA and a second wire was reached down to the LAD. During deploying balloon angioplasty to LAD lesion, he developed asystole 


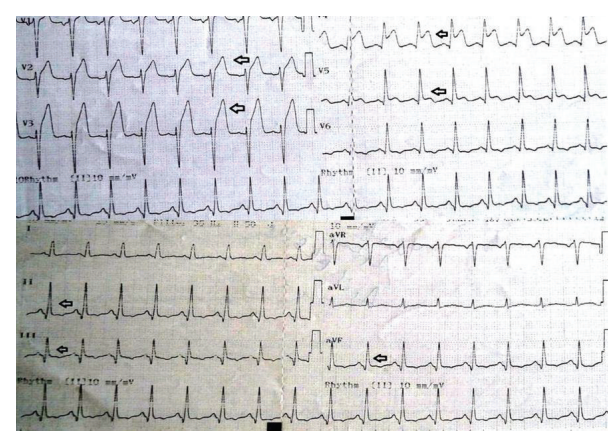

FIGURE 1: ST segment elevations in precordial leads.

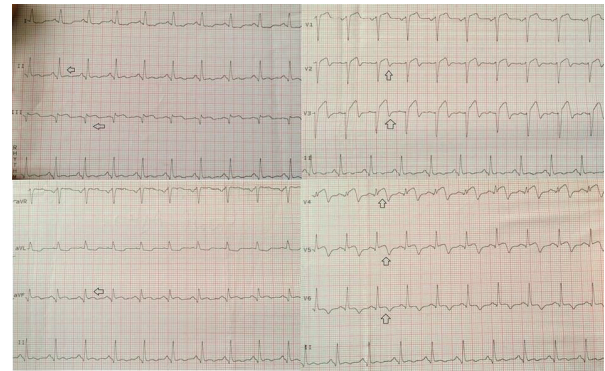

FIGURE 2: Partial ST segment resolution after fibrinolytic therapy in precordial leads.

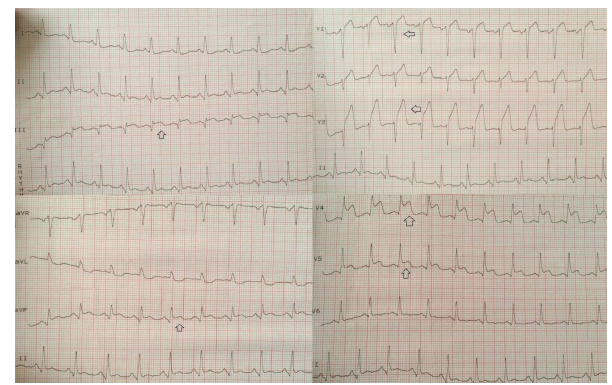

FIGURE 3: ST segment elevations in both inferior and precordial leads after fibrinolytic therapy.

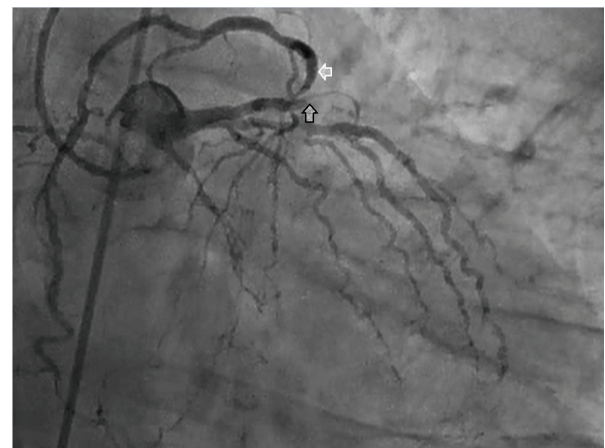

FIGURE 4: Left anterior descending coronary artery with total occlusion (black arrow) and right coronary artery from proximal segment of left anterior descending coronary artery (white arrow).

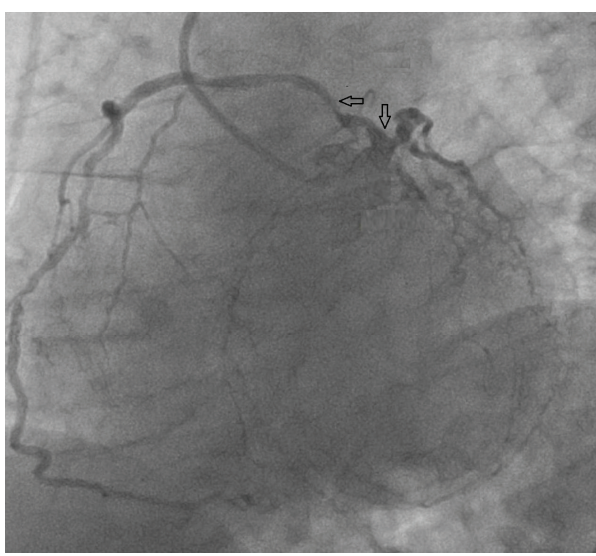

FIGURE 5: Single coronary ostium and severe ostial lesion of right coronary artery.

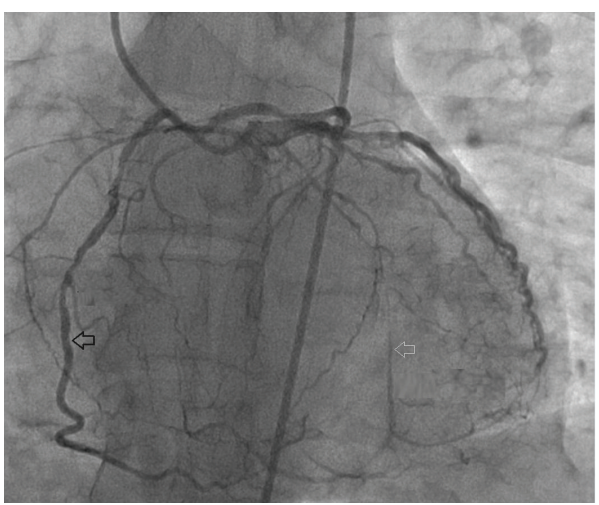

FIGURE 6: Right coronary artery from proximal left anterior descending coronary artery (black arrow) and retrograde filling of circumflex coronary artery (white arrow).

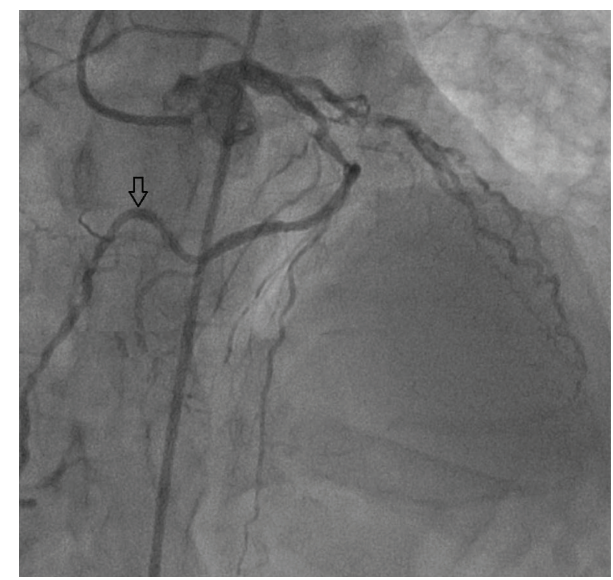

FIGURE 7: Coronary angiographic appearance of the right coronary artery.

and subsequently the patient had cardiopulmonary arrest. Despite all our efforts, we lost the patient during cardiac catheterization. 


\section{Discussion}

CAA are rare and frequently benign congenital abnormalities of coronary circulation. Although cardiac catheterization is accepted as gold standard for defining CAA, noninvasive multislice computed tomography (CT) plays a substantial role in terms of illustrating the anatomy. Generally, most of the patients were diagnosed incidentally during conventional CA. Coronary artery anomalies have been identified in $0.2 \%$ to $1.3 \%$ of coronary angiograms and $0.3 \%$ in autopsy series $[2,3]$. According to a Turkish serial which consisted of 53.655 patients who underwent $\mathrm{CA}$, the estimated incidence of anomalous origin of the RCA from the left sinus of Valsalva or left main coronary artery is $0.1 \%$ [4]. Anomalous origin of the RCA from the left sinus of Valsalva traversing between the aorta and pulmonary artery is far more common presentation [5]. Anomalous origin of the RCA from the LAD artery is very rare and frequently benign compared to other types of anomalous origin of the RCA [6]. Sohrabi and his colleagues demonstrated that there was a high prevalence of atherosclerotic coronary artery disease in patients who had an anomalous RCA originating from left coronary sinus [7]. According to a study by Garg and his colleagues, incidence of coronary atherosclerosis in patients with CAA was found to be \%10.25 [8]. On the other hand, most of the literatures do not demonstrate a strong relation between CAA and atherosclerosis. Except for a few case reports, myocardial infarction is rarely observed in patients with a history of CAA [9]. Comparing with normal population PCI in patients with CAA has considerable technical difficulties [10]. Postmortem study or CT angiography would have been helpful in order to define the exact course of the coronary artery but unfortunately we did not have the chance to perform any of them. In our case, the patient had a single coronary artery ostium which was occluded by a thrombotic lesion spreading both LAD and ostium of RCA. Even though we did not encounter difficulties during cannulation process, patient's unstable condition and high ischemic burden made our attempt unsuccessful.

\section{Conclusion}

In conclusion, cardiologists should bear in mind that CAA might have vicious outcomes and patients with these anomalies must be evaluated delicately.

\section{Conflict of Interests}

The authors state that they have no conflict of interests (COI).

\section{References}

[1] B. J. Maron, J. J. Doerer, T. S. Haas, D. M. Tierney, and F. O. Mueller, "Sudden deaths in young competitive athletes: analysis of 1866 deaths in the United States, 1980-2006," Circulation, vol. 119, no. 8, pp. 1085-1092, 2009.

[2] E. Ghersin, D. Litmanovich, A. Ofer et al., "Anomalous origin of right coronary artery: diagnosis and dynamic evaluation with multidetector computed tomography," Journal of Computer Assisted Tomography, vol. 28, no. 2, pp. 293-294, 2004.

[3] C. Frescura, C. Basso, G. Thiene et al., "Anomalous origin of coronary arteries and risk of sudden death: a study based on an autopsy population of congenital heart disease," Human Pathology, vol. 29, no. 7, pp. 689-695, 1998.

[4] S. Turkmen, C. E. Cagliyan, F. Poyraz et al., "Coronary arterial anomalies in a large group of patients undergoing coronary angiography in southeast Turkey," Folia Morphologica, vol. 72, no. 2, pp. 123-127, 2013.

[5] A. J. Taylor, J. P. Byers, M. D. Cheitlin, and R. Virmani, "Anomalous right or left coronary artery from the contralateral coronary sinus: 'High-risk' abnormalities in the initial coronary artery course and heterogeneous clinical outcomes," American Heart Journal, vol. 133, no. 4, pp. 428-435, 1997.

[6] C. Duran, M. Kantarci, I. Durur Subasi et al., "Remarkable anatomic anomalies of coronary arteries and their clinical importance: a multidetector computed tomography angiographic study," Journal of Computer Assisted Tomography, vol. 30, no. 6, pp. 939-948, 2006.

[7] B. Sohrabi, A. Habibzadeh, and E. Abbasov, "The incidence and pattern of coronary artery anomalies in the North-West of Iran: a coronary arteriographic study," Korean Circulation Journal, vol. 42, no. 11, pp. 753-760, 2012.

[8] N. Garg, S. Tewari, A. Kapoor, D. K. Gupta, and N. Sinha, "Primary congenital anomalies of the coronary arteries: a coronary arteriographic study," International Journal of Cardiology, vol. 74, no. 1, pp. 39-46, 2000.

[9] J. H. Kim, G. J. Ha, M. J. Seong et al., "Anomalous origin of the left circumflex coronary artery from the first diagonal branch presented as acute myocardial infarction," Korean Circulation Journal, vol. 41, no. 10, pp. 612-614, 2011.

[10] M. Lanzieri, K. Khabbaz, R. N. Salomon, and C. Kimmelstiel, "Primary angioplasty of an anomalous left main coronary artery: diagnostic and technical considerations," Catheterization and Cardiovascular Interventions, vol. 58, no. 2, pp. 185-188, 2003. 


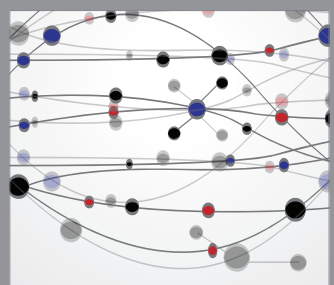

The Scientific World Journal
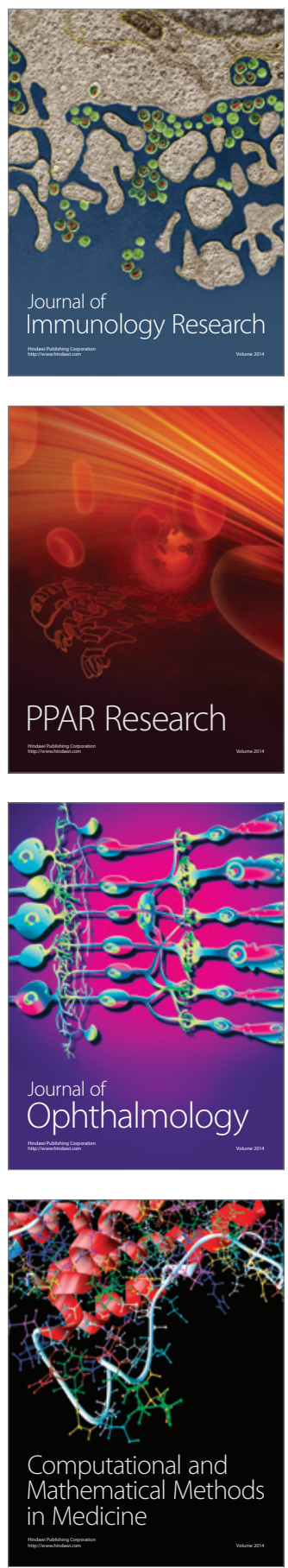

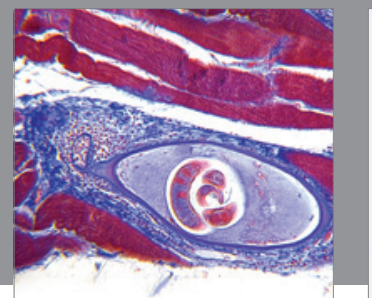

Gastroenterology

Research and Practice
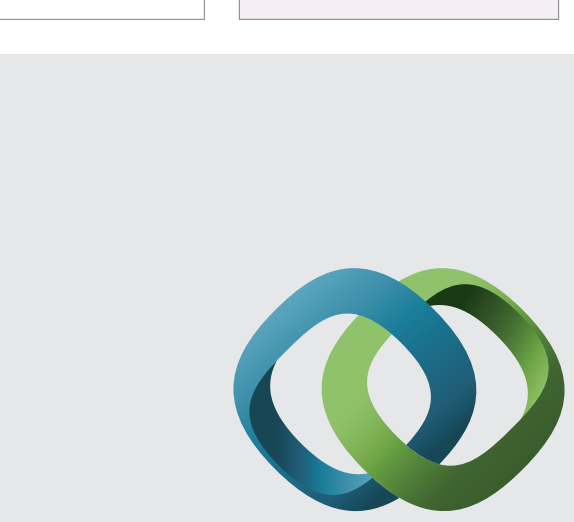

\section{Hindawi}

Submit your manuscripts at

http://www.hindawi.com
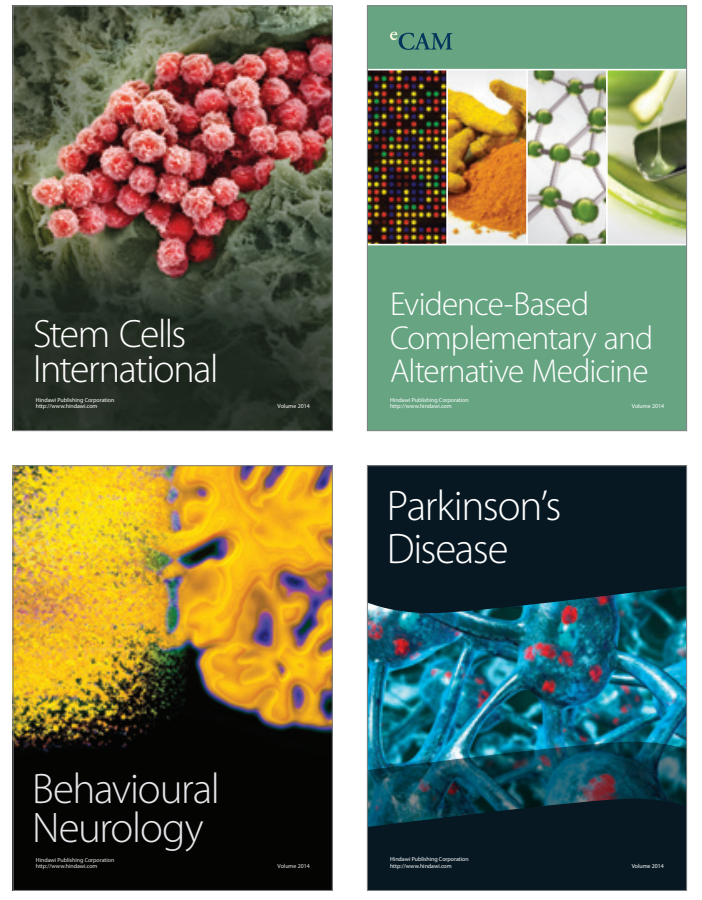
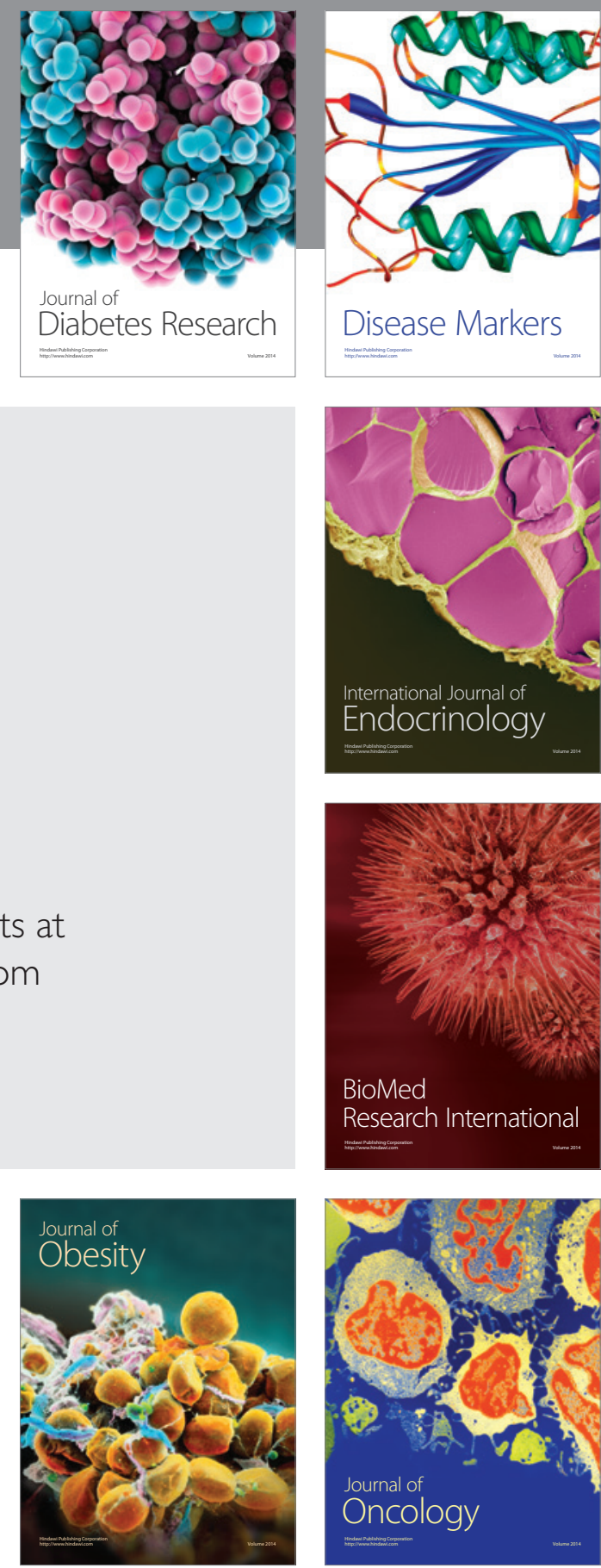

Disease Markers
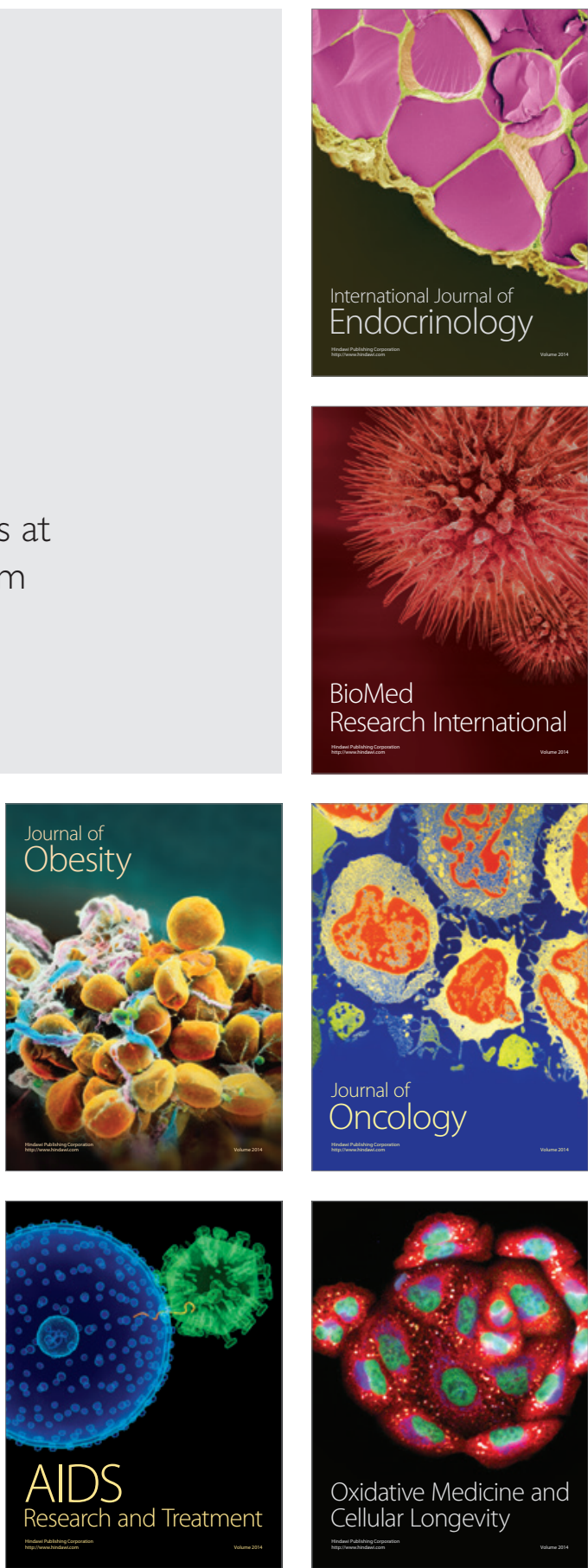